\title{
The mathematical progress of students with an intellectual disability in inclusive classrooms: results of a longitudinal study
}

\section{Susanne Schnepel ${ }^{1}$ (D) Helena Krähenmann ${ }^{1} \cdot$ Rachel Sermier Dessemontet $^{2}$. Elisabeth Moser Opitz ${ }^{1}$}

Received: 18 June 2018 / Revised: 11 September 2019 / Accepted: 19 November 2019 /

Published online: 9 December 2019

(C) The Author(s) 2019

\begin{abstract}
Little is known about the mathematical development of students with intellectual disabilities (ID) in inclusive classrooms. It is important to have a researchbased understanding of the subject since inclusive education is becoming the norm in many countries, and an increasing number of students with an ID now attend mainstream schools. We investigated the learning gains of 38 students with ID from 31 grades 2 and 3 inclusive classrooms. Data on mathematics achievement were collected at the beginning and at the end of one school year. A cluster analysis revealed four homogeneous groups that differed significantly in their mathematical progress. Students in the same cluster improved in the same subskills. Prior knowledge is a significant predictor for progress and explains more variance than IQ. In addition, the acquisition of the quantitynumber concept, especially the linkage of quantities and numbers, seems to be an important factor for mathematical development. These results show that mathematics instruction needs to be tailored to the specific knowledge profiles of students.
\end{abstract}

Keywords Inclusive mathematical instruction · Intellectual disability · Numerical development · Quantity-number concept

Susanne Schnepel

susanne.schnepel@uzh.ch

1 University of Zurich, Freiestrasse 36, 8032 Zurich, Switzerland

2 School of Education Vaud, Avenue de Cour 33, 1014 Lausanne, Switzerland 


\section{Introduction}

A major aim of inclusive instruction is the social and academic participation of all students. In this paper, the focus is on academic achievement in mathematics in students with an intellectual disability (ID) ${ }^{1}$ in inclusive classrooms. While inclusivity can mean anything from students with special educational needs (SEN) simply being present in regular classrooms, to creating classrooms that meet the academic and social needs of students with SEN, to aiming to foster equity in the classroom community (see Jordan 2018), most field studies do not differentiate between these concepts of inclusive education. Therefore, in this paper, we use the term "inclusive classroom" in the broadest possible sense.

The literature on the impact of inclusive instruction on students with SEN often does not distinguish between children with different categories of special needs. Many studies report positive outcomes for the achievement levels of students with SEN (e.g., Freeman and Alkin 2000; Ruijs and Peetsma 2009). However, only a few focus on students with ID, Cole et al. (2004) carried out a longitudinal study comparing students with mild disabilities in inclusive settings with those in separate classrooms. The study revealed no significant difference between the groups in reading and in mathematics. Peetsma et al. (2001) also found no significant difference between students with mild ID in mainstream and specialist classrooms over the course of 2 years. However, after 4 years, students with mild ID in mainstream schools made more progress in mathematics than students with mild ID in separate classrooms. In a study by Laws et al. (2000), children with Down syndrome improved significantly more than their age-matched peers in vocabulary, grammar, and digit span, but not in nonlanguage-based memory. A longitudinal study by Sermier Dessemontet et al. (2012) showed that children with ID included in regular classrooms made slightly more progress in literacy skills than children attending special schools. However, no difference between the groups was found in mathematics. These results demonstrate the paucity of research on the mathematical development of students in inclusive classrooms. Furthermore, only the study by Peetsma et al. (2001) found significant longterm effects on mathematical attainment after 4 years. Schnepel (2019) conducted an intervention study in inclusive classrooms with students with $\mathrm{ID}^{2}$. The experimental group received a program to foster basic numerical competences while the control group carried out a program designed to support social participation. No effect from the mathematical intervention could be found. These results raise some questions. Is the mathematical learning success of students with ID restricted because of their intellectual limits? What progress do students with ID make in mathematics during one school year, and in which mathematics skills? Are there differences between students with different achievement levels? The present study aims to answer these questions by analyzing the mathematical learning gains of students with ID in inclusive classrooms in elementary school.

\footnotetext{
${ }^{1}$ Intellectual disability is an umbrella term for a broad range of different syndromes and cognitive impairments. The criteria used to define the sample of students with ID in this study will be described in the "Methods" section. According to the definition of the American Association on Intellectual and Developmental Disabilities (AAIDD), "Intellectual disability is characterized by significant limitations both in intellectual functioning and in adaptive behavior as expressed in conceptual, social, and practical adaptive skills. This disability originates before age 18 (Schalock et al. 2007)."

${ }^{2}$ The study was conducted using the same sample as the study presented in this paper.
} 


\section{Numerical development of students with ID}

It is generally agreed that numeracy skills are critical in the daily lives of people with ID. Numeracy skills are indispensable for making sense of and ordering the world. They are important for everyday life and therefore for independent living and social participation (Cheong et al. 2017; Faragher and Brown 2005), for example, when paying for things, checking one's change, or cooking. In the broader sense, numeracy also includes the ability to contextualize and fit the meanings of numbers into real world situations (Cheong et al. 2017). However, only few studies have investigated the mathematical development of numeracy skills in students with ID. We report these findings in the following section. Before doing so, it is necessary to summarize the current state of knowledge on the numerical development of typically developing children.

\section{Insights on the numerical development of typically developing children}

Early numerical skills are often defined as "number sense." Number sense is an umbrella term for the mathematical competences of preschoolers, and it includes counting skills and principles and basic number knowledge (e.g., comparing quantities, reading numbers). Even though different authors use (slightly) different tasks to define number sense, they all agree on its importance for arithmetical development in primary school. Studies from the last decade show that these skills predict the mathematical development of students in the first years of school (Aunio and Niemivirta 2010; Desoete et al. 2012; Friso-van den Bos et al. 2014; Jordan et al. 2007; Jordan et al. 2010a; Kolkman et al. 2013, Krajewski and Schneider 2009; Stock et al. 2010; Toll et al. 2016; Weißhaupt et al. 2006). Jordan et al. (2007) report that number sense performance in kindergarten accounted for $66 \%$ of the variance of first graders' arithmetic achievement. According to Stock et al. (2010), number sense explains $50 \%$ of the variance of mathematical performance of students aged 6 to 7 years. In a study by Krajewski and Schneider (2006), $26 \%$ of the variance of mathematical performance at the end of grade 4 was predicted by number sense achievement at the end of kindergarten. Socio-economic status (Jordan and Levine 2009; Schuchardt et al. 2014; Ulferts and Anders 2015) and working memory (e.g., Toll et al. 2016; Mähler and Schuchardt 2016) also have an impact on mathematical development.

When considering number sense, differentiating between non-symbolic skills (e.g., comparing dots, ordering cards with a different number of dots) and symbolic skills (number naming, comparing numbers), and the link between these skills, has been shown to be important (Friso-van den Bos et al. 2014; Kolkman et al. 2013; Toll et al. 2016). According to Kolkman et al. (2013), the mapping of numbers and quantities is predicted by symbolic, but not by non-symbolic skills. In a longitudinal study with children from kindergarten through third grade, Missall et al. (2012) found that symbolic skills (comparing numbers, inserting a missing number in a number sequence) are the most robust factors for predicting later math performance.

The acquisition of these skills has been described by a number of different models, all of which emphasize the importance of counting skills and the linkage of numbers and quantities (Aunio and Räsänen 2016; Sarama and Clements 2009; Jordan et al. 2010b; Krajewski and Schneider 2009). In this study, we use Krajewski's model of numerical development (Krajewski and Ennemoser 2013; Krajewski and Schneider 2009), which has 
also been found to be applicable when describing the numerical development of students with ID (Moser Opitz et al. 2014; Garrote et al. 2015). The model has three levels (Krajewski and Schneider 2009). Each level is described by different skills (Table 1). Level I consists of basic numerical skills. At this level, children start to recite number sequences and recognize number words as special words. They are also able to discern quantities and to compare them in terms of more, less, and the same. However, they are not yet able to link numbers with quantities. That competence is a characteristic of level II, which is described as the acquisition of the quantity-number concept. The concept develops in two phases: the imprecise and the precise quantity-number concept. In the first phase, children can determine if the numbers correspond to the categories a bit, much, or very much, but they cannot link numbers to their corresponding exact quantities. This imprecise knowledge becomes ever more precise and, in time, children understand the number word sequence as the order of precisely increasing quantities. Therefore, being able to recite the number sequence correctly is crucial for the development of the precise quantity-number concept. Finally, children are able to link number words and numbers to quantities. According to Krajewski and Schneider (2009) this " ... represents the most important concept for the successful acquisition of elementary school mathematics."

At level III, children can compose and decompose numbers and identify the differences between numbers. They can define differences between two numbers using another number. This level of competence is important for learning addition and subtraction and understanding equations. Although the model defines levels, it should not be interpreted in a strictly hierarchical fashion. The level of competence depends on the representation of tasks (e.g., the use of manipulatives) and the number domain. A student can have skills at level III for numbers up to 10 but have a level I understanding of numbers up to 100 . The Krajewski model can help to elucidate the mathematical competence and learning gains of students with ID. This application is discussed in the following section.

\section{Numerical competences and development of students with ID}

Research shows that the mathematical development of students with ID is similar to that of students without ID but delayed and slower (Baroody 1999; Bashash et al. 2003;

Table 1 Summary of the Krajewski model for acquiring early quantity-number competences (Krajewski and Schneider 2009)

\begin{tabular}{ll}
\hline Level/topics & Subskills \\
\hline $\begin{array}{l}\text { Level I: basic numerical } \\
\text { skills }\end{array}$ & $\begin{array}{c}\text { Quantity discrimination: differentiating between discrete quantities, comparing } \\
\text { quantities and using the words "more," "less," or "the same amount," reciting } \\
\text { number words, exact number-word sequences. }\end{array}$ \\
$\begin{array}{l}\text { Level II: quantity-number } \\
\text { concept }\end{array}$ & $\begin{array}{l}\text { Imprecise quantity-number linkage: differentiating between "little," "much," and } \\
\text { "very much." } \\
\text { Precise quantity-number linkage: Counting objects, distinguishing number words. } \\
\text { Relations between quantities without reference to number words, number } \\
\text { invariance/conservation. }\end{array}$ \\
$\begin{array}{c}\text { Composition and decomposition of numbers, number relationships (4 is one more } \\
\text { than 3). }\end{array}$
\end{tabular}


Brankaer et al. 2011). Bashash et al. (2003) investigated the understanding of counting principles and the principle of cardinality among students with ID aged from 7 to 18 . No difference was found when they were compared with a control group of students with the same mental age. There was a high degree of correlation between counting competence and the number concept (e.g., "make a set of $n$ "). However, as the systematic research review of Abdelahmeed (2007) reports, many students with Down syndrome have problems with counting competence and therefore also have problems with the comprehension of the principle of cardinality and, in turn, with the number concept.

Brankaer et al. (2011) compared the processing of numbers and quantities between students without ID and those with mild ID (aged 10). Students with mild ID showed a similar, but delayed, development of number magnitude processing. They needed more time for the acquisition of the linkage of numbers to quantities and the numerical magnitude representation than did their age-matched peers. In a second study, Brankaer et al. (2013) showed that students with mild ID (aged 8) performed worse than agematched peers on a symbolic and a non-symbolic representation task. Working memory could not explain these difficulties. According to Garrote et al. (2015), many students aged 6 to 18 with mild and moderate ID have acquired basic numerical skills on level I of the Krajewski model. However, items on level II (linkage of numbers and quantities) and level III (part-whole relationships) were more difficult for most of them.

Sermier Dessemontet et al. (2019) analyzed the patterns and profiles of progress in numerical skills of students with ID (aged 6 to 10 years) during one school year. The students attended special schools for students with ID. The results revealed four groups with different profiles, which reflect the structure of the Krajewski model. Students in three groups made significant progress, but those in one group did not. Those students who had inconsistent basic numerical skills and had no understanding of cardinality at the pre-test made less progress than those who had already acquired cardinality at the beginning of the study.

To sum up, research results show that number magnitude processing, especially the linkage of numbers to magnitudes, seems to be a major problem for many students with ID.

\section{Summary and research questions}

The current state of research reveals a lacuna: Longitudinal research on the mathematical development of students with ID is lacking, especially in the setting of inclusive classrooms. The results from Sermier Dessemontet et al. (2019) show that the learning gains of students with ID in special schools are dependent on specific competencesthe ability to link numbers and quantities. This leads to the following research questions, inspired by Sermier Dessemontet et al. (2019) and adapted for this study:

- What profiles in numerical skills are displayed by students with ID in grades 2 and 3 who are being taught in inclusive classrooms?

- Are there quantitative and qualitative differences in the progress made by groups of students with ID during one school year that conform to distinct profiles in numerical skills? 
- Which factors have an impact on the mathematical learning gains of students with ID in inclusive classrooms?

\section{Methods}

\section{Participants}

An invitation letter was sent to teachers of classrooms in grades 2 and 3 in Germanand French-speaking parts of Switzerland-where at least one child was officially diagnosed with ID by a school psychologist (cutoff IQ < 75). The teachers voluntarily chose whether to participate. In order for a student to participate in the study, their parents had to provide written consent. We excluded six students from the analysis because their IQ was higher than 75 (for details, see Schnepel 2019). The final sample consisted of 38 students with ID (16 girls, 22 boys) in 31 inclusive classrooms ${ }^{3}, 27$ of whom came from the German-speaking part of Switzerland and 11 from the Frenchspeaking part (Table 2). Most participants had an ID with unspecified etiology $(n=32)$. Six students had Down syndrome. Because the population of students with ID included in regular classrooms is small, the participants were recruited in grade $2(n=30)$ and grade $3(n=8)$. Twenty-three of the students had German or French as first language. Fifteen students had another first language.

Information on how inclusion was implemented in the classrooms was gathered from a video study of the sample classrooms. Two key aspects of inclusive education were evaluated: the implementation of joint learning situations (whole class interactions and group learning that included all students) and of differentiation (differentiated learning goals on class level and for students with ID). The videos showed that teachers either provided joint learning situations or offered differentiated learning goals. This means that different models of inclusive education were realized, from learning in communities to separate learning situations for children with ID (Krähenmann et al. 2019).

\section{Measures}

Mathematics achievement The mathematics achievement of the students was tested twice, once at the beginning ( $\mathrm{t} 1$ ) and again at the end of the school year ( $\mathrm{t} 2)$. Each child with ID was tested on their own in a quiet room of the school, using selected subtests of TEDI-MATH (Kaufmann et al. 2009; van Nieuwenhoven and Grégoire 2015). The test ran for $45 \mathrm{~min}$. When necessary, there was a break half-way through the test. TEDIMATH is a standardized test to assess the basic numeracy and arithmetic skills of children from kindergarten to grade 3, which is also suitable for students with ID (Garrote et al. 2015). The instrument includes the following subtests: procedural and conceptual counting, writing and reading numbers, seriation of quantities and numbers, number conservation, decomposition of numbers, computation (addition/subtraction) supported by pictures, base-ten system, and computation with equations (addition/ subtraction). Most of the subtests cover the number domain from 1 to 20. The subtests

\footnotetext{
${ }_{3}^{3}$ Data on all variables were also collected from the typically developing children, but these are not reported in this paper.
} 
Table 2 Demographic characteristics of the sample of students with ID

\begin{tabular}{lc}
\hline Variable & Total sample \\
\hline Students & 38 \\
German-speaking CH & 27 \\
French-speaking CH & 11 \\
Gender & 22 \\
Boys & 16 \\
Girls & \\
First language & 23 \\
German/French & 15 \\
Other & 23 \\
\hline
\end{tabular}

writing and reading numbers include numbers up to $1000^{4}$. Cronbach's alpha for the total test score was 0.98 for pre- and for post-test. Cronbach's alpha for the subtests ranges from 0.64 to 0.98 .

Intelligence The intelligence scores of the students with ID were retrieved from their school records. If this score was not available, students were asked to complete CFT 1R (Weiß and Osterland 2013). In a few cases, due to the lower limit of the IQ score (55) in the CFT, SON-R (Tellegen et al. 2007) was used instead. The limitations of this methodology are reported in the discussion section. The average IQ of the sample was $62.03(\mathrm{SD}=8.63)$.

\section{Procedure}

The mathematics assessment was carried out by trained test administrators. Background information about the students with ID (e.g., language spoken at home, etiology) and educational setting (e.g., hours of support by special education teacher) was gathered using a teacher questionnaire. Each class was taught by a regular teacher. A special education teacher was present for a certain number of hours (between 1.5 and $5 \mathrm{~h}$ ) per week during mathematical instruction $(M=3.5 \mathrm{~h}, \mathrm{SD}=1.19)$.

\section{Results}

\section{Descriptives}

At t1, the mean score for TEDI-MATH was $M=41.34(\mathrm{SD}=25.09)$ and it increased to $M=55.50(\mathrm{SD}=28.32)$ at $\mathrm{t} 2($ Table 3$)$. The high standard deviations indicate the wide

\footnotetext{
${ }^{4}$ Six subtests (comparing quantities of dots, Arabic numerals, number words, and distances of two numbers to another number, inclusion task) had to be excluded because the probability of answering correctly was $50 \%$ (Moser Opitz et al. 2015).
} 
Table 3 Participant characteristics of the sample

\begin{tabular}{lc}
\hline Variable & Total sample \\
\hline Math t1 & $41.34(25.09)$ \\
Math t2 & $55.50(28.32)$ \\
IQ & $62.03(8.63)$ \\
Age (months) & $99.84(8.20)$ \\
\hline
\end{tabular}

range of mathematics achievement among students with ID. IQ $(M=62.03, \mathrm{SD}=8.63)$ is below the average of the total population. The mean age is 8.32 years $(\mathrm{SD}=0.68)$.

Significant correlations between mathematics achievement at $\mathrm{t} 1$ and $\mathrm{t} 2, \mathrm{IQ}$, age, and grade have been found (Table 4). IQ correlates with the students' age ( $r=0.38, p<$ $0.05)$ as well with their grade $\left(\operatorname{eta}^{2}=0.13, p<0.05\right.$ ): the older the students, the higher the IQ. There were no correlations between mathematics achievement and gender. Mathematics achievement and first language do not correlate at $\mathrm{t} 1$, but have a small correlation at $\mathrm{t} 2\left(\mathrm{eta}^{2}=0.11, p<0.05\right)$. The same pattern is apparent in the correlation between IQ and first language $\left(\mathrm{eta}^{2}=0.05, p<0.05\right.$ ) (Table 5). Students who do not speak French or German at home are more likely to achieve higher scores in mathematics at $\mathrm{t} 2$ and have a higher IQ. This might be because students with a first language other than German or French may have been diagnosed with ID because of a low IQ test score that was the result of language problems rather than an actual intellectual disability. Grade and mathematics achievement at $\mathrm{t} 1$ and $\mathrm{t} 2$ correlate significantly.

\section{Predictor of numerical competences}

Multiple hierarchical regression analyses were conducted to investigate the relationship between mathematics achievement at $\mathrm{t} 1$ and other variables. When conducting hierarchical regression analyses, the order in which the variables are inserted into the model have to be carefully considered. It is assumed that IQ and age (as an indicator how long a child has attended school) have an impact on mathematical achievement. Therefore, the variables were included in the model in the following order: IQ, age, then first language German and French (Table 6). The model explained $45.6 \%$ of the variance $\left(R^{2}=0.46, F(3,34)=9.50, p<0.001\right) . R^{2}$ significantly changed to $0.44(p<0.001)$ by adding the IQ and to $0.46(p<0.01)$ by adding age. No significant impact of first language was found ${ }^{5}$.

In a second model, the impact of IQ, math at t1, age, and first language German and French on math at $\mathrm{t} 2^{6}$ was tested. As our hypothesis was that math achievement at $\mathrm{t} 1$ was an important predictor for the learning gains of students, it was inserted in step two. The results (Table 7) indicate that the four predictors explain $86.3 \%$ of the variance $\left(R^{2}\right.$ $=0.86, F(4,33)=52.06, p<0.001) . R^{2}$ changed significantly to 0.84 when math $\mathrm{t} 1$ was

\footnotetext{
${ }^{5}$ Analyses were also conducted with the video study variables - joint learning situations and differentiation. These variables were found to have no impact on mathematical achievement; therefore, the results are not presented.

${ }^{6}$ Age was not included as a predictor because the number of predictors had to be $<4$ (due to the sample size of $n=38$ ). In addition, age was not a significant predictor in a separate model, which is not reported.
} 
Table 4 Intercorrelations (Pearson's $r$ )

\begin{tabular}{llll}
\hline & Math $\mathrm{t} 2$ & Math $\mathrm{t} 1$ & IQ \\
\hline Math $\mathrm{t} 2$ & & & \\
Math t1 & $0.92 * * *$ & & \\
IQ & $0.49^{* *}$ & $0.57 * * *$ & $0.38^{*}$ \\
Age & $0.43^{* *}$ & $0.52^{* * *}$ & \\
\hline
\end{tabular}

$* p<0.05, * * p<0.01, * * * p<0.001$

inserted. Unexpectedly, $R^{2}$ also increased significantly to 0.86 when first language was included. Adding the variables of age and IQ did not have a significant impact on the predictions for $\mathrm{t} 2$.

The results show that students with high mathematics achievement at $\mathrm{t} 1$ performed better at $\mathrm{t} 2$.

However, results from other studies of the mathematical development of students with ID suggest that mathematical progress depends on very specific areas of prior knowledge. To test this hypothesis, a hierarchical cluster analysis was conducted using Ward's method to detect different profiles of mathematical learning gains.

\section{Cluster analysis}

The cluster analysis was based on mathematics achievement at $\mathrm{t} 1$ and $\mathrm{t} 2$. The data best fits a four-cluster structure. The four subgroups comprise seven to 14 students (Descriptives: Table 8).

The four groups differ statistically significantly in mathematics achievement at $\mathrm{t}$ $(F(3,34)=135.65, p<0.001)$ and at $\mathrm{t} 2(F(3,34)=124.69, p<0.001)$, which was confirmed using the Bonferroni post hoc test $(p<0.05)$.

For IQ, a significant difference was found between clusters 1 and $3(p<0.05)$ and clusters 1 and $4(p<0.001)$. On average, students in clusters 3 and 4 had significantly higher IQ than students in cluster 1 . The mean age differed significantly between cluster 1 and cluster $4(p<0.05)$. The students in the four clusters progressed in different subskills during one school year (Table 9; Wilcoxon signed-rank test was computed).

The students' scores increased significantly between $\mathrm{t} 1$ and $\mathrm{t} 2$ in all four clusters. Each cluster has distinct characteristics and represents a different profile.

Table 5 Intercorrelations $\left(\mathrm{eta}^{2}\right)$

\begin{tabular}{llll}
\hline & Math t1 & Math t2 & IQ \\
\hline Gender & 0.02 & 0.07 & 0.00 \\
First language & 0.04 & $0.11^{*}$ & $0.05^{*}$ \\
Grade & $0.28^{* * *}$ & $0.19^{* *}$ & $0.13^{*}$ \\
\hline
\end{tabular}

$* p<0.05, * * p<0.01, * * * p<0.001$ 
Table 6 Hierarchical regressions analysis summary for predicting math t1

\begin{tabular}{llccccr}
\hline Step & Predictor variable & $B$ & $S E B$ & $\beta$ & $R^{2}$ & $\Delta R^{2}$ \\
\hline 1 & IQ & 1.16 & 0.41 & $0.40^{* *}$ & 0.33 & 0.33 \\
2 & Age & 1.17 & 0.43 & $0.38^{*}$ & 0.44 & 0.11 \\
3 & First language & -7.20 & 6.67 & -0.142 & 0.46 & 0.02 \\
\hline
\end{tabular}

$* p<0.05, * * p<0.01, * * * p<0.001$

\section{Profiles of children in the four clusters}

\section{Cluster 1: Basic knowledge, no quantity-number concept}

Cluster $1(n=9)$ includes four boys and five girls in grade 2 (first language German or French). Six of the nine have a Down syndrome diagnosis; all children with Down syndrome are in this cluster. IQ ranges between 49 and $72(M=55.0, \mathrm{SD}=8.0)$. These students made little, but significant, progress from $t 1$ to $t 2(t=-2.50, p<0.05, n=9)$. At 2 , the majority of these students succeeded in reading and writing numbers up to 10 and counted quantities up to 10 . Most of them had an understanding of counting principles; they understood the number sequence as a unidirectional whole structure or as a forward-directed recited sequence which consists of separate words (Fuson 1988). Four students could count up to a given number (6 or 9). The skills of the students in cluster 1 can be assigned to level I of Krajewski's model: reciting the number sequence, reading and writing numbers. At 2 , some students could already demonstrate the initial skills of level II (linkage of small quantities and number words).

\section{Cluster 2: Basic knowledge up to 100, quantity-number concept up to 20}

Cluster 2 is composed of eight boys and six girls ( $n=2$ in grade 3, $n=12$ in grade 2; 6 with German or French as a first language, eight with another first language). IQ is between 42 and $72(M=61.14, \mathrm{SD}=8.46)$. At t 1 , all students could read and write numbers up to 10 and could read and write some numbers up to 20 . Most of them counted up to 20 correctly. The conceptual counting task and the seriation of quantities and numbers indicated that they had already acquired the quantity-number concept at the beginning of the school year. The students progressed in counting, number relationships, and addition. They consolidated their procedural counting skills and could count up to 31 at $\mathrm{t} 2$. In addition, they could read and

Table 7 Regressions analysis summary for predicting math $\mathrm{t} 2$

\begin{tabular}{llcccrr}
\hline Step & Predictor variable & $B$ & $S E B$ & $\beta$ & $R^{2}$ & $\Delta R^{2}$ \\
\hline 1 & IQ & -0.254 & 0.26 & -0.08 & 0.24 & 0.24 \\
2 & Math t1 & 1.06 & 0.10 & $0.94^{* * *}$ & 0.84 & 0.60 \\
3 & Age & -0.05 & 0.27 & -0.01 & 0.84 & 0.00 \\
4 & First language & -9.01 & 3.90 & $-0.16^{*}$ & 0.86 & 0.02 \\
\hline
\end{tabular}

$* p<0.05, * * p<0.01, * * * p<0.001$ 
Table 8 Demographic and cognitive characteristics of each cluster

\begin{tabular}{|c|c|c|c|c|c|c|}
\hline & \multicolumn{4}{|l|}{ Cluster } & \multirow[t]{2}{*}{$F(3,34)$} & \multirow[t]{2}{*}{$p$} \\
\hline & 1) Basic knowledge & 2) $\mathrm{QNC} 20$ & 3) $\mathrm{QNC} 100$ & 4) Computation & & \\
\hline Students & 9 & 14 & 8 & 7 & & \\
\hline IQ & $55.00(8.00)_{a, b}$ & $62.14(8.46)$ & $67.38(7.01)_{\mathrm{a}}$ & $66.71(4.68)_{\mathrm{b}}$ & 4.95 & $<0.01$ \\
\hline Age (t1) & $94.78(6.80)_{\mathrm{c}}$ & $99.64(7.08)$ & $99.75(9.85)$ & $106.86(5.96)_{\mathrm{c}}$ & 3.41 & $<0.05$ \\
\hline Math t1 & $8.11(6.90)$ & $35.71(6.53)$ & $56.88(8.51)$ & $77.57(7.68)$ & 135.65 & $<0.001$ \\
\hline Math $\mathrm{t} 2$ & $13.89(8.01)$ & $53.21(9.26)$ & $77.00(9.91)$ & $89.00(5.13)$ & 124.69 & $<0.001$ \\
\hline \multicolumn{7}{|l|}{ Gender } \\
\hline Male & 4 & 8 & 5 & 5 & & \\
\hline Female & 5 & 6 & 3 & 2 & & \\
\hline \multicolumn{7}{|l|}{ Grade } \\
\hline 2nd & 9 & 12 & 6 & 3 & & \\
\hline $3 \mathrm{rd}$ & 0 & 2 & 2 & 4 & & \\
\hline \multicolumn{7}{|c|}{ First language } \\
\hline $\mathrm{G} / \mathrm{F}$ & 9 & 6 & 4 & 4 & & \\
\hline Other & 0 & 8 & 4 & 3 & & \\
\hline
\end{tabular}

The means in IQ and age with the same subscript differ significantly with $p<0.05$ according to Bonferroni post hoc test

$Q N C$, quantity-number concept

write some numbers up to 100 (number of tens). Although there was significant progress in the decomposition of small numbers, none of the students achieved the maximum score. The numeracy skills of these students are on the first two levels of the Krajewski's model of numerical development. They show basic numerical skills (level I) up to 100, and they are able to link quantities with numbers in the number domain up to 20. Level III skills (number relationships) seem to depend on the format of the item (e.g., support with representations).

\section{Cluster 3: Basic knowledge up to 100, solid knowledge of quantity-number concept, first computation skills}

Cluster 3 comprises five boys and three girls ( $n=6$ grade $2, n=2$ grade 3 ). Half of the students speak German or French as their first language. Their IQ ranges from 52 to 73 $(M=67.38, \mathrm{SD}=7.01)$. These students started at $\mathrm{t} 1$ with numeracy skills up to 20 , successfully linked quantities and numbers, and carried out addition problems with small numbers. They extended their numerical knowledge by learning to read and write numbers up to 100 . They also made significant progress in understanding the structure of the base-ten system. So, at $\mathrm{t} 2$, these students demonstrated basic numerical skills up to 100 (level I) and had a solid knowledge of the quantity-number concept.

\section{Cluster 4: Basic skills up to 1000 , computation, understanding the base-ten system}

The majority of the children in this cluster (five boys, two girls) were in grade 3 (4 of 7). Four of the seven speak German or French as their first language. Their IQ ranges 
Table 9 Means and standard deviations of subtests and intragroup differences between $\mathrm{t} 1$ and $\mathrm{t} 2$

\begin{tabular}{|c|c|c|c|c|c|c|c|c|}
\hline \multirow[b]{2}{*}{ Subtest (max.) } & \multicolumn{2}{|c|}{$\begin{array}{l}\text { 1) Basic } \\
\text { knowledge }\end{array}$} & \multicolumn{2}{|c|}{ 2) $\mathrm{QNC} 20$} & \multicolumn{2}{|c|}{ 3) $\mathrm{QNC} 100$} & \multicolumn{2}{|c|}{ 4) Computation } \\
\hline & $M_{\mathrm{t} 1}$ & $M_{\mathrm{t} 2}$ & $M_{\mathrm{t} 1}$ & $M_{\mathrm{t} 2}$ & $M_{\mathrm{t} 1}$ & $M_{\mathrm{t} 2}$ & $M_{\mathrm{t} 1}$ & $M_{\mathrm{t} 2}$ \\
\hline $\begin{array}{l}\text { Procedural counting } \\
\quad(12)\end{array}$ & $\begin{array}{c}1.11 \\
(1.3- \\
6)\end{array}$ & $\begin{array}{c}1.22 \\
(1.7- \\
9)\end{array}$ & $\begin{array}{c}6.07 \\
(2.1- \\
3)\end{array}$ & $\begin{array}{l}7.86^{* * *} \\
(2.21)\end{array}$ & $\begin{array}{c}8.38 \\
(2.2- \\
6)\end{array}$ & $\begin{array}{c}10.63 \\
(1.77)\end{array}$ & $\begin{array}{c}10.57 \\
(1.5- \\
1)\end{array}$ & $\begin{array}{l}11.14 \\
(1.22)\end{array}$ \\
\hline $\begin{array}{l}\text { Conceptual counting } \\
\text { (6) }\end{array}$ & $\begin{array}{c}0.67 \\
(0.8- \\
7)\end{array}$ & $\begin{array}{c}2.56^{*} \\
(1.0- \\
1)\end{array}$ & $\begin{array}{c}4.79 \\
(1.1- \\
2)\end{array}$ & $5.07(1.00)$ & $\begin{array}{c}4.38 \\
(1.4- \\
1)\end{array}$ & $\begin{array}{l}5.38 \\
(1.19)\end{array}$ & $\begin{array}{c}4.71 \\
(1.6- \\
0)\end{array}$ & $\begin{array}{l}5.43 \\
(0.79)\end{array}$ \\
\hline Writing numbers (18) & $\begin{array}{c}1.00 \\
(1.3- \\
2)\end{array}$ & $\begin{array}{c}1.78 \\
(1.4- \\
8)\end{array}$ & $\begin{array}{c}5.50 \\
(2.1- \\
4)\end{array}$ & $\begin{array}{l}8.71 * * \\
(2.37)\end{array}$ & $\begin{array}{c}8.25 \\
(1.3- \\
9)\end{array}$ & $\begin{array}{l}13.25 * \\
(2.05)\end{array}$ & $\begin{array}{c}13.29 \\
(2.3- \\
6)\end{array}$ & $\begin{array}{r}16.43^{*} \\
(2.44)\end{array}$ \\
\hline Reading numbers (15) & $\begin{array}{c}2.44 \\
(2.5- \\
1)\end{array}$ & $\begin{array}{c}4.33 * \\
(3.6- \\
4)\end{array}$ & $\begin{array}{c}6.86 \\
(2.6- \\
0)\end{array}$ & $\begin{array}{r}11.43 * * * \\
(1.65)\end{array}$ & $\begin{array}{c}9.63 \\
(1.7- \\
7)\end{array}$ & $\begin{array}{r}13.75 * \\
(0.89)\end{array}$ & $\begin{array}{c}13.71 \\
(1.6- \\
0)\end{array}$ & $\begin{array}{l}14.85 \\
(0.38)\end{array}$ \\
\hline $\begin{array}{l}\text { Seriation of quantities } \\
\text { (2) }\end{array}$ & $\begin{array}{c}0.00 \\
(0.0- \\
0)\end{array}$ & $\begin{array}{c}0.22 \\
(0.4- \\
4)\end{array}$ & $\begin{array}{c}0.93 \\
(0.9- \\
2)\end{array}$ & $1.00(0.96)$ & $\begin{array}{c}1.88 \\
(0.3- \\
5)\end{array}$ & $\begin{array}{l}1.50 \\
(0.76)\end{array}$ & $\begin{array}{c}1.71 \\
(0.7- \\
6)\end{array}$ & $\begin{array}{l}1.71 \\
(0.49)\end{array}$ \\
\hline $\begin{array}{l}\text { Seriation of numbers } \\
\text { (1) }\end{array}$ & $\begin{array}{c}0.00 \\
(0.0- \\
0)\end{array}$ & $\begin{array}{c}0.00 \\
(0.0- \\
0)\end{array}$ & $\begin{array}{c}0.43 \\
(0.5- \\
1)\end{array}$ & $0.71(0.47)$ & $\begin{array}{c}0.75 \\
(0.4- \\
6)\end{array}$ & $\begin{array}{l}0.88 \\
(0.35)\end{array}$ & $\begin{array}{c}1.00 \\
(0.0- \\
0)\end{array}$ & $\begin{array}{l}1.00 \\
(0.00)\end{array}$ \\
\hline $\begin{array}{l}\text { Number conservation } \\
\text { task (4) }\end{array}$ & $\begin{array}{c}0.89 \\
(1.4- \\
5)\end{array}$ & $\begin{array}{c}0.67 \\
(0.8- \\
7)\end{array}$ & $\begin{array}{c}0.79 \\
(1.5- \\
8)\end{array}$ & $1.50(0.94)$ & $\begin{array}{c}2.13 \\
(1.1- \\
3)\end{array}$ & $\begin{array}{l}1.50 \\
(1.41)\end{array}$ & $\begin{array}{c}2.00 \\
(1.6- \\
3)\end{array}$ & $\begin{array}{l}2.71 \\
(1.50)\end{array}$ \\
\hline $\begin{array}{l}\text { Computat. supp. by } \\
\text { pictures (6) }\end{array}$ & $\begin{array}{c}1.44 \\
(1.5- \\
1)\end{array}$ & $\begin{array}{c}2.00 \\
(1.2- \\
3)\end{array}$ & $\begin{array}{c}3.71 \\
(1.6- \\
4)\end{array}$ & $4.36(1.45)$ & $\begin{array}{c}5.00 \\
(2.0- \\
7)\end{array}$ & $\begin{array}{l}5.38 \\
(0.52)\end{array}$ & $\begin{array}{c}5.57 \\
(0.5- \\
4)\end{array}$ & $\begin{array}{l}5.71 \\
(0.49)\end{array}$ \\
\hline $\begin{array}{l}\text { Decomposition of } \\
\text { numbers }(6)\end{array}$ & $\begin{array}{c}0.11 \\
(0.3- \\
3)\end{array}$ & $\begin{array}{c}0.44 \\
(0.5- \\
3)\end{array}$ & $\begin{array}{c}0.50 \\
(0.6- \\
5)\end{array}$ & $\begin{array}{c}1.36^{*} \\
(1.45)\end{array}$ & $\begin{array}{c}2.00 \\
(1.6- \\
9)\end{array}$ & $\begin{array}{l}3.00 \\
(2.07)\end{array}$ & $\begin{array}{c}4.71 \\
(1.7- \\
0)\end{array}$ & $\begin{array}{l}5.57 \\
(0.79)\end{array}$ \\
\hline Base-ten system (7) & $\begin{array}{c}0.00 \\
(0.0- \\
0)\end{array}$ & $\begin{array}{c}0.22 \\
(0.4- \\
4)\end{array}$ & $\begin{array}{c}0.71 \\
(0.9- \\
1)\end{array}$ & $1.29(1.38)$ & $\begin{array}{c}1.75 \\
(1.4- \\
9)\end{array}$ & $\begin{array}{l}4.88^{*} \\
(2.42)\end{array}$ & $\begin{array}{c}2.43 \\
(2.3- \\
0)\end{array}$ & $\begin{array}{l}4.43 \\
(2.30)\end{array}$ \\
\hline Addition (11) & $\begin{array}{c}0.22 \\
(0.4- \\
4)\end{array}$ & $\begin{array}{c}0.11 \\
(0.3- \\
3)\end{array}$ & $\begin{array}{c}2.93 \\
(2.2- \\
0)\end{array}$ & $\begin{array}{l}5.50 * \\
(3.28)\end{array}$ & $\begin{array}{c}8.25 \\
(1.8- \\
3)\end{array}$ & $\begin{array}{l}8.38 \\
(2.00)\end{array}$ & $\begin{array}{c}9.43 \\
(1.1- \\
3)\end{array}$ & $\begin{array}{l}10.00 \\
(1.00)\end{array}$ \\
\hline Subtraction (7) & $\begin{array}{c}0.00 \\
(0.0- \\
0)\end{array}$ & $\begin{array}{c}0.00 \\
(0.0- \\
0)\end{array}$ & $\begin{array}{c}0.79 \\
(1.3- \\
1)\end{array}$ & $2.57(2.53)$ & $\begin{array}{c}2.63 \\
(3.1- \\
6)\end{array}$ & $\begin{array}{l}5.25 \\
(2.49)\end{array}$ & $\begin{array}{c}4.86 \\
(1.5- \\
7)\end{array}$ & $\begin{array}{l}6.14 * \\
1.22)\end{array}$ \\
\hline Problem solving (4) & $\begin{array}{c}0.22 \\
(0.6- \\
7)\end{array}$ & $\begin{array}{c}0.22 \\
(0.4- \\
4)\end{array}$ & $\begin{array}{c}1.71 \\
(0.9- \\
9)\end{array}$ & $1.86(1.46)$ & $\begin{array}{c}1.88 \\
(1.5- \\
6)\end{array}$ & $\begin{array}{l}3.25 \\
(0.71)\end{array}$ & $\begin{array}{c}3.57 \\
(0.5- \\
4)\end{array}$ & $\begin{array}{l}3.86 \\
(0.38)\end{array}$ \\
\hline
\end{tabular}

Significant differences in mean (Wilcoxon): $* p<0.05, * * p<.01, * * * p<.001$

from 58 to $73(M=66.71, \mathrm{SD}=4.68)$. They started at t1 having already acquired the quantity-number concept, able to read and write numbers up to 100 , and able to decompose numbers, add, and subtract. By $\mathrm{t} 2$, they had made significant progress in writing numbers up to 1000 and subtraction with small numbers $(<10)$. Although a 
ceiling effect in the mathematics test can be assumed for some subtests, the progress measured in the subtests shows that these students extended and deepened their understanding on all levels, in basic numerical skills, in the quantity-number concept, and in number relationships.

\section{Discussion}

Conducting a classroom-based research on students with ID is always challenging, because sample sizes are usually small and heterogeneous, as they were in this study. The sample and its subgroups were small. The students' IQ had not all been determined using the same protocol, although it should be noted that Moser Opitz and Ramseier (2012) showed that different IQ measures do not necessarily lead to different results. A further complication was the fact that a surprisingly high number of students had a first language other than the language of instruction. This casts doubt on the reliability of the ID diagnosis because some students may well have been incorrectly diagnosed with ID due to their reduced competence in French or German. However, the composition of the sample reflects the realities in the field. Because of budget and time constraints, no information could be collected on students' working memory or communication skills. Furthermore, a ceiling effect in the mathematics test could have resulted in the students in cluster 4 having lower learning gains than the students in cluster 3 . These limitations have to be kept in mind when interpreting the findings.

\section{Predictors of mathematics achievement}

The results show that for $\mathrm{t} 1$, IQ is the only significant predictor of mathematics achievement. However, at $\mathrm{t} 2$, when prior knowledge (mathematics achievement at $\mathrm{t} 1$ ) was added into the model, IQ was no longer a significant predictor. In line with other studies (e.g., Baroody 1999), prior knowledge seems to be the most important predictor and more important than IQ.

Surprisingly, first language was also a significant predictor at 2 . Students with a first language other than German or French achieved higher scores in mathematics and have a higher IQ. As mentioned above, it can be assumed that these students have been given a misdiagnosis of ID because the language of instruction is not their mother tongue, which is most often the case with the children of migrants. For this reason, it is important that any future study assesses the reliability of ID diagnostic processes. In addition, "second language" should be an important consideration when implementing intervention programs.

\section{Different profiles—different learning gains}

Four distinct profiles were identified using cluster analysis; each cluster has its own profile. This result emphasizes the high significance of number sense for mathematical development (Aunio and Niemivirta 2010; Desoete et al. 2012; Jordan et al. 2007; Jordan et al. 2010a; Kolkman et al. 2013, Krajewski and Schneider 2009; Stock et al. 2010). In particular, the study corroborates the findings of previous studies which have shown that the quantity-number concept is a crucial milestone in numerical 
development (Brankaer et al. 2011; Garrote et al. 2015). Students who had already acquired the quantity-number concept were more likely to make progress than students who could not link quantities with numbers. The result also casts doubt on the efficacy of programs for students with ID that focus on computation. It appears that progress in computation is only possible after acquiring number sense and having an understanding of the quantity-number concept.

A further interesting finding is that students in the different clusters show improvement in specific skills and at different achievement levels. The findings on number decomposition provide a good example. As other studies have also noted (Garrote et al. 2015), this was a very difficult task for many students. Nevertheless, students in all clusters made progress. Students in cluster 2 significantly improved their number decomposition with small number skills, whereas students in clusters 3 and 4 made progress in problems with decomposition in the base-ten system. This supports the assumption that mathematics instruction for students with ID has to be very tailored and adaptive.

The high number of students with Down syndrome in cluster 1 could indicate that these students have specific numerical profiles. However, other studies suggest (e.g., Faragher and Clarke 2014) that this result is mostly likely a coincidence and that no unique "mathematical profile" for students with Down syndrome exists.

Finally, the results also show that at any given time, a student may be operating on one level at one number domain but a different one in another (Krajewski and Schneider 2009). For example, basic numerical skills up to 100 (reading, writing, number sequence) can exist parallel to flexible counting competence and a quantitynumber concept up to 20 .

\section{Specific results for inclusive classrooms}

It is interesting to compare the results of this study with those from the study by Sermier Dessemontet et al. (2019), which investigated students with ID who were attending special schools. Both studies yielded four profiles, and in both studies, the linkage of numbers and quantities emerged as a critical factor for learning gains. However, an interesting difference can be noted. Approximately half of the sample in Sermier Dessemontet's study made almost no progress (cluster 1). This result might be an artifact of the selection processes. It can be assumed that students with more severe ID are allocated to special education schools, while students with mild ID more often have the opportunity to attend inclusive classrooms. It appears that inclusive education in Switzerland is designed to accommodate children above a certain minimum achievement level. To test this hypothesis, analyses with matched pairs of students in inclusive and special education classrooms have to be carried out.

\section{Conclusion}

Research shows that inclusive education has a positive impact on the language skills of students with ID, but there is little or no evidence for any beneficial impact on the learning of mathematics (see the "Introduction" section). It is difficult to ascertain whether the mathematical learning success of students with ID is restricted because of their intellectual limits or because of insufficient or inappropriate support. Our results 
confirm previous findings: Number sense, especially the quantity-number concept, is an important predictor for mathematical learning gains. But our findings also show that the very specific profiles of mathematics competence of students with ID have to be taken into account. Therefore, fostering these competences has to be adapted to the respective profile. However, sound research about successful and appropriate support is still lacking. The data also show that it is important to ensure that students have a firm understanding of number sense before moving on to computational skills. Therefore, programs for teaching mathematics to students with ID which focus primarily on addition and subtraction have to be critically re-examined.

The results of the cluster analysis indicate that the students with ID had very variable needs. This makes inclusive mathematics instruction very challenging for teachers. On the one hand, teachers have to select appropriate activities and materials for each student within very heterogeneous groups of students and differentiate learning goals and activities. On the other hand, joint learning situations and cooperative learning settings are important for social inclusion. A framework and materials for inclusive mathematics instruction which includes differentiation and ideas on how to adapt learning goals for students with ID could offer support for teachers. Such frameworks are being developed (e.g., Krähenmann et al. 2019; Schnepel 2019), however, their positive impact on the achievement of the students has yet to be proven.

To sum up, future research on the mathematics instruction of students with ID in inclusive classrooms has to address several challenges: It needs to emphasize the acquisition of the quantity-number concept, adapt interventions to the students' specific profiles, and analyze students' development.

Open Access This article is distributed under the terms of the Creative Commons Attribution 4.0 International License (http://creativecommons.org/licenses/by/4.0/), which permits unrestricted use, distribution, and reproduction in any medium, provided you give appropriate credit to the original author(s) and the source, provide a link to the Creative Commons license, and indicate if changes were made.

\section{References}

Abdelahmeed, H. (2007). Do children with Down syndrome have difficulty in counting and why? International Journal of Special Education, 22(2), 129-139.

Aunio, P., \& Niemivirta, M. (2010). Predicting children's mathematical performance in grade one by early numeracy. Learning and Individual Differences, 20(5), 427-435.

Aunio, P., \& Räsänen, P. (2016). Core numerical skills for learning mathematics in children aged five to eight years-a working model for educators. European Early Childhood Education Research Journal, 24(5), 684-704.

Baroody, A. J. (1999). The development of basic counting, number, and arithmetic knowledge among children classified as mentally handicapped. International Review of Research in Mental Retardation, 22(22), 51103.

Bashash, L., Bochner, S., \& Outhred, L. (2003). Counting skills and number concepts of students with moderate intellectual disabilities. International Journal of Disability, Development and Education, 50(3), 325-345.

Brankaer, C., Ghesquière, P., \& de Smedt, B. (2011). Numerical magnitude processing in children with mild intellectual disabilities. Research in Developmental Disabilities, 32(6), 2853-2859.

Brankaer, C., Ghesquière, P., \& de Smedt, B. (2013). The development of numerical magnitude processing and its association with working memory in children with mild intellectual disabilities. Research in Developmental Disabilities, 34(10), 3361-3371. 
Cheong, J. M., Walker, Z. M., \& Rosenblatt, K. (2017). Numeracy abilities of children in grades 4 to 6 with mild intellectual disability in Singapore. International Journal of Disability, Development and Education, 64(2), 150-168.

Cole, C. M., Waldron, N., \& Maijd, M. (2004). Academic progress of students across inclusive and traditional setting. Mental Retardation, 42(2), 136-144.

Desoete, A., Ceulemans, A., de Weerdt, F., \& Pieters, S. (2012). Can we predict mathematical learning disabilities from symbolic and non-symbolic comparison tasks in kindergarten? Findings from a longitudinal study. The British journal of educational psychology, 82(1), 64-81.

Faragher, R., \& Brown, R. I. (2005). Numeracy for adults with Down syndrome: It's a matter of quality of life. Journal of Intellectual Disability Research, 49(10), 761-765.

Faragher, R., \& Clarke, B. (2014). Mathematics profile of the learner with Down syndrome. In R. Faragher \& B. Clarke (Eds.), Educating learners with Down syndrome. Research, theory and practice with children and adolescents (pp. 119-145). New York: Routledge.

Freeman, S. F. N., \& Alkin, M. C. (2000). Academic and social attainments of children with mental retardation in general education and special education settings. Remedial and Special Education, 21, 3-18.

Friso-van den Bos, I., Kroesbergen, E. H., \& Van Luit, J. E. (2014). Number sense in kindergarten children: Factor structure and working memory predictors. Learning and Individual Differences, 33, 23-29.

Fuson, K. C. (1988). Children's counting and concepts of number. Springer series in cognitive development. New York: Springer.

Garrote, A., Moser Opitz, E., \& Ratz, C. (2015). Mathematische Kompetenzen von Schülerinnen und Schülern mit dem Förderschwerpunkt geistige Entwicklung: Eine Querschnittstudie. Empirische Sonderpädagogik, 7(1), 24-40.

Jordan, A. (2018). The supporting effective teaching project: 1. Factors influencing student success in inclusive elementary classrooms. Exceptionally Education International, 28(3), 10-27.

Jordan, N. C., \& Levine, S. C. (2009). Socioeconomic variation, number competence, and mathematics learning difficulties in young children. Developmental Disabilities Research Reviews, 15(1), 60-68.

Jordan, N. C., Kaplan, D., Locuniak, M. N., \& Ramineni, C. (2007). Predicting first-grade math achievement from developmental number sense trajectories. Learning Disabilities Research \& Practice, 22(2), 36-46.

Jordan, N. C., Glutting, J., \& Ramineni, C. (2010a). The importance of number sense to mathematics achievement in first and third grades. Learning and Individual Differences, 20(2), 82-88.

Jordan, N. C., Glutting, J., Ramineni, C., \& Watkins, M. W. (2010b). Validating a number sense screening tool for use in kindergarten and first grade: Prediction of mathematics proficiency in third grade. School Psychology Review, 39(2), 181-195.

Kaufmann, L., Nuerk, H.-C., Graf, M., Krinzinger, H., Delazer, M., \& Willmes, K. (2009). TEDI-MATH: Test zur Erfassung numerisch-rechnerischer Fertigkeiten vom Kindergarten bis zur 3. Klasse. Bern: Huber.

Kolkman, M. E., Kroesbergen, E. H., \& Leseman, P. P. (2013). Early numerical development and the role of non-symbolic and symbolic skills. Learning and Instruction, 25, 95-103.

Krähenmann, H., Moser Opitz, E., Schnepel, S. \& Stöckli, M. (2019). Inclusive mathematics instruction: A conceptual framework and selected research results of a video study. In D. Kollosche, R. Marcone, M. Knigge, M.G. Penteado \& O. Skovsmose (Eds), Inclusive mathematics education. State-of-the-art research from Brazil and Germany (pp. 179-196). Cham: Springer.

Krajewski, K., \& Ennemoser, M. (2013). Entwicklung und Diagnostik der Zahl-Grössen-Verknüpfung zwischen 3 und 8 Jahren. In M. Hasselhorn, A. Heinze, \& W. Schneider (Eds.), Diagnostik mathematischer Kompetenzen (pp. 41-65). Göttingen: Hogrefe.

Krajewski, K., \& Schneider, W. (2006). Mathematische Vorläuferfertigkeiten im Vorschulalter und ihre Vorhersagekraft für die Mathematikleistungen bis zum Ende der Grundschulzeit. Psychologie in Erziehung und Unterricht, 53, 246-262.

Krajewski, K., \& Schneider, W. (2009). Early development of quantity to number-word linkage as a precursor of mathematical school achievement and mathematical difficulties: Findings from a four-year longitudinal study. Learning and Instruction, 19(6), 513-526.

Laws, G., Byrne, A., \& Buckley, S. (2000). Language and memory development in children with Down syndrome at mainstream schools and special schools: A comparison. Educational Psychology, 20(4), $447-457$.

Mähler, C., \& Schuchardt, K. (2016). The importance of working memory for school achievement in primary school children with intellectual or learning disabilities. Research in Developmental Disabilities, 58, 1-8. https://doi.org/10.1016/j.ridd.2016.08.007.

Missall, K. N., Mercer, S. H., Martínez, R. S., \& Casebeer, D. (2012). Concurrent and longitudinal patterns and trends in performance on early numeracy curriculum-based measures in kindergarten through third grade. Assessment for Effective Intervention, 37(2), 95-106. 
Moser Opitz, E., \& Ramseier, E. (2012). Rechenschwach oder nicht rechenschwach? Eine kritische Auseinandersetzung mit Diagnoseinstrumenten unter besonderer Berücksichtigung von älteren Schülerinnen und Schülern. Lernen und Lernstörungen, 1, 99-117.

Moser Opitz, E., Garrote, A., \& Ratz, C. (2014). Mathematische Kompetenzen von Schülerinnen und Schülern mit geistiger Behinderung: Erste Ergebnisse einer Pilotstudie. Sonderpädagogische Förderung heute, 59(1), 19-31.

Moser Opitz, E., Schnepel, S., Ratz, C., \& Iff, R. (2015). Diagnostik und Förderung mathematischer Kompetenzen. In J. Kuhl, \& N. Euker (Eds.), Evidenzbasierte Diagnostik und Förderung von Kindern und Jugendlichen mit intellektueller Beeinträchtigung (pp. 123-151). Bern: Hogrefe.

Peetsma, T., Vergeer, M., Roeleveld, J., \& Karsten, S. (2001). Inclusion in Education: Comparing pupils' development in special and regular education. Educational Review, 53(2), 125-135.

Ruijs, N. M., \& Peetsma, T. T. (2009). Effects of inclusion on students with and without special educational needs reviewed. Educational Research Review, 4(2), 67-79.

Sarama, J. \& Clements, D.H. (2009). Early childhood mathematics education research: Routledge.

Schalock, R. L., Luckasson, R. A., \& Shogren, K. A. (2007). The renaming of mental retardation: Understanding the change to the term intellectual disability. Intellectual and Developmental Disabilities, 45(2), 116-124.

Schnepel, S. (2019). Mathematische Förderung von Kindern mit einer intellektuellen Beeinträchtigung - eine Längsschnittstudie in inklusiven Klassen. Münster: Waxmann.

Schuchardt, K., Piekny, J., Grube, D., \& Mähler, C. (2014). Kognitive und häusliche Einflüsse auf den Erwerb früher numerischer Kompetenzen. Zeitschrift für Entwicklungspsychologie und Pädagogische Psychologie, 46(1), 24-34.

Sermier Dessemontet, R., Bless, G., \& Morin, D. (2012). Effects of inclusion on the academic achievement and adaptive behaviour of children with intellectual disabilities. Journal of intellectual disability research $\therefore$ JIDR, 56(6), 579-587.

Sermier Dessemontet, R., Moser Opitz, E. \& Schnepel, S. (2019). The profiles and patterns of progress in numerical skills of elementary school students with mild and moderate intellectual disability. International Journal of Disability, Development and Education, 24(2), 1-15.

Stock, P., Desoete, A., \& Roeyers, H. (2010). Detecting children with arithmetic disabilities from kindergarten: Evidence from a 3-year longitudinal study on the role of preparatory arithmetic abilities. Journal of Learning Disabilities, 43(3), 250-268.

Tellegen, P. J., Laros, J. A., \& Petermann, F. (2007). SON-R 2 1/2-7: Non-verbaler Intelligenztest. Göttingen: Hogrefe.

Toll, S. W., Kroesbergen, E. H., \& Van Luit, J. E. (2016). Visual working memory and number sense: Testing the double deficit hypothesis in mathematics. The British journal of educational psychology, 86(3), 429445 .

Ulferts, H., \& Anders, Y. (2015). Effects of ECEC on academic outcomes in literacy and mathematics: Meta-analysis of European longitudinal studies. http://ecec-care. org/fileadmin/careproject/Publications/reports/summaries/Summary_CARE_WP4_D4_2_ Metaanalysis_internal.pdf. Accessed 23 Apr 2017.

van Nieuwenhoven, C., \& Grégoire, J. (2015). TEDI-MATH: Test diagnostique des compétences de base en mathématiques du CE2 à la $5 e$ : manuel. Montreuil: ECPA-Pearson.

Weiß, R. H., \& Osterland, J. (2013). CFT 1-R: Grundintelligenztest Skala 1. Göttingen: Hogrefe.

Weißhaupt, S., Peucker, S., \& Wirtz, M. (2006). Diagnose mathematischen Vorwissens im Vorschulalter und Vorhersage von Rechenleistungen und Rechenschwierigkeiten in der Grundschule. Psychologie Erziehung Unterricht, 53, 236-245.

Publisher's note Springer Nature remains neutral with regard to jurisdictional claims in published maps and institutional affiliations. 